\title{
Effects of inhibiting PDK-1 expression in bone marrow mesenchymal stem cells on osteoblast differentiation in vitro
}

\author{
YIGUANG BAI $^{1,2^{*}}$, QIONG ZHANG ${ }^{3 *}$, QUAN ZHOU $^{4,5}$, YANAN ZHANG $^{4}$, HAIBIN NONG $^{1}$, \\ MINGFU LIU ${ }^{1}$, ZHUOHUA SHI ${ }^{1}$, GAOFENG ZENG ${ }^{3}$ and SHAOHUI ZONG ${ }^{1,6}$
}

\begin{abstract}
${ }^{1}$ Department of Spine Osteopathia, The First Affiliated Hospital of Guangxi Medical University, Guangxi Medical University, Nanning, Guangxi 530021; ${ }^{2}$ Department of Orthopedics, Nanchong Central Hospital, The Second Clinical Institute of North Sichuan Medical College, Nanchong, Sichuan 637000; ${ }^{3}$ Department of Nutrition and Food Hygiene, College of Public Hygiene of Guangxi Medical University; ${ }^{4}$ Collaborative Innovation Center of Guangxi Biological Medicine, Guangxi Medical University, Nanning, Guangxi 530021; ${ }^{5}$ Department of Emergency, The Hongqi Hospital Affiliated to Mudanjiang Medical University, Mudanjiang, Heilongjiang 157001; ${ }^{6}$ Research Centre for Regenerative Medicine and Guangxi Key Laboratory of Regenerative Medicine, Guangxi Medical University, Nanning, Guangxi 530021, P.R. China
\end{abstract}

Received May 30,2020; Accepted November 2, 2020

DOI: $10.3892 / \mathrm{mmr} .2020 .11757$

\begin{abstract}
Osteoblasts are the main functional cells in bone formation, which are responsible for the synthesis, secretion and mineralization of bone matrix. The PI3K/AKT signaling pathway is strongly associated with the differentiation and survival of osteoblasts. The 3-phosphoinositide-dependent protein kinase-1 (PDK-1) protein is considered the master upstream lipid kinase of the PI3K/AKT cascade. The present study aimed to investigate the role of PDK-1 in the process of mouse osteoblast differentiation in vitro. In the BX-912 group, BX-912, a specific inhibitor of PDK-1, was added to osteoblast induction medium (OBM) to treat bone marrow mesenchymal stem cells (BMSCs), whereas the control group was treated with OBM alone. Homozygote PDK $1^{\text {flox/flox }}$ mice were designed and generated, and were used to obtain BMSCs ${ }^{\text {PDK1flox/flox }}$ Subsequently, an adenovirus containing Cre recombinase enzyme (pHBAd-cre-EGFP) was used to disrupt the PDK-1 gene in BMSCs ${ }^{\text {PDK1flox/flox }}$; this served as the pHBAd-cre-EGFP group and the efficiency of the disruption was verified.
\end{abstract}

Correspondence to: Professor Shaohui Zong, Department of Spine Osteopathia, The First Affiliated Hospital of Guangxi Medical University, Guangxi Medical University, 22 Shuangyong Road, Nanning, Guangxi 530021, P.R. China

E-mail: xiaohui3008@126.com

Professor Gaofeng Zeng, Department of Nutrition and Food Hygiene, College of Public Hygiene of Guangxi Medical University, 22 Shuangyong Road, Nanning, Guangxi 530021, P.R. China

E-mail: 1685858372@qq.com

*Contributed equally

Key words: osteoblasts, gene knockout, adenovirus, Cre recombinase enzyme, 3-phosphoinositide-dependent protein kinase 1
Western blot analysis demonstrated that the protein expression levels of phosphorylated (p)-PDK1 and p-AKT were gradually increased during the osteoblast differentiation process. Notably, BX-912 treatment and disruption of the PDK-1 gene with pHBAd-cre-EGFP effectively reduced the number of alkaline phosphatase (ALP)-positive cells and the optical density value of ALP activity, as well as the formation of cell mineralization. The mRNA expression levels of PDK-1 in the pHBAd-cre-EGFP group were significantly downregulated compared with those in the empty vector virus group on days 3-7. The mRNA expression levels of the osteoblast-related genes RUNX2, osteocalcin and collagen I were significantly decreased in the BX-912 and pHBAd-cre-EGFP groups on days 7 and 21 compared with those in the control and empty vector virus groups. Overall, the results indicated that BX-912 and disruption of the PDK-1 gene in vitro significantly inhibited the differentiation and maturation of osteoblasts. These experimental results provided an experimental and theoretical basis for the role of PDK-1 in osteoblasts.

\section{Introduction}

Osteoporosis is a systemic metabolic disease associated with age, which is accompanied by a significant economic and psychological burden to patients and their families (1). At present, the drugs used to treat osteoporosis have several side effects and other deficiencies (2); therefore, further determining the pathogenesis of osteoporosis and identifying novel treatment targets is of great economic and social significance. Under normal physiological conditions, osteoblasts serve an important role in bone formation. Osteoblasts are the main functional cells in bone formation, and are responsible for the synthesis, secretion and mineralization of bone matrix; the proliferation and differentiation of osteoblasts are regulated by a variety of growth factors $(3,4)$. Therefore, understanding the mechanism underlying osteoblast differentiation has a vital clinical significance for the treatment of osteoporosis. 
The PI3K/AKT signaling pathway is involved in the regulation of cell proliferation, differentiation, apoptosis and glucose transport, particularly in apoptosis and cell survival (5). PI3K is a key control point in several apoptotic pathways. When PI3K is activated, second messengers PIP2 and PIP3 can be induced. AKT is an important downstream target of PI3K and PIP3, which can interact with PIP3 recruited on the plasma membrane, and then be partially phosphorylated and activated by 3-phosphoinositide-dependent protein kinase-1 (PDK-1) to regulate downstream pathways and promote cell survival (6). An increasing body of evidence has reported that the PI3K/AKT signaling pathway regulates the proliferation and differentiation of osteoblasts (7). Notably, the PDK-1 protein has attracted increasing attention in recent years; however, to the best of our knowledge, the role of PDK-1 in osteoblast differentiation has not been systematically studied.

Bones are affected by the balance in osteoblast-mediated bone formation and osteoclast-mediated bone resorption. Our previous study demonstrated that inhibiting the expression of PDK-1 significantly inhibited the differentiation and maturation of osteoclasts (8). Therefore, the aim of present study was to determine the role of PDK-1 in osteoblast differentiation.

\section{Materials and methods}

Ethics statement. The present study was approved by the Ethics Committee of the Guangxi Medical University (Nanning, China; approval no. 201910012).

Materials and reagents. Fetal bovine serum (FBS) and Dulbecco's modified Eagle medium were purchased from Gibco (Thermo Fisher Scientific, Inc.). Osteoblast induction medium (OBM; cat. no. MUBMX-90021) was purchased from Cyagen Biosciences, Inc. Primary antibodies specific to t-PDK1(rabbit; cat. no. 5662; 1:1,000), p-PDK1 (rabbit; cat. no. 3438; 1:1,000), t-Akt (rabbit; cat. no. 4685; 1:1,000), p-Akt (rabbit; cat. no. 13038; 1:1,000), GAPDH (rabbit; cat. no. $5174 ; 1: 1,000)$ and horseradish peroxidase-conjugated IgG secondary antibody (anti-rabbit; cat. no. 5127; 1:2,000) were purchased from Cell Signaling Technology, Inc. The E.Z.N.A. Total RNA kit I (cat. no. R6834-02) was purchased from Omega Bio-Tek, Inc. The Alkaline Phosphatase (ALP) Staining kit, ALP Activity Assay kit and Alizarin Red S Staining kit were purchased from Beyotime Institute of Biotechnology. The PrimeScript ${ }^{\mathrm{TM}}$ RT Reagent kit was obtained from Takara Bio, Inc. Adenoviral vectors encoding Cre recombinase (PHBAd-cre-GFP) were purchased from Hanbio Biotechnology Co., Ltd. BX-912 (PDK-1 specific inhibitor) was purchased from Selleck Chemicals. The commercial Cell Counting Kit-8 (CCK-8) assay kit was purchased from Beyotime Institute of Biotechnology.

Animals. A total of three male C57BL/6 mice (age, 4-6 weeks; weight, 10-16 g; homozygote PDK- $1^{\text {flox/flox }}$ ) were designed and provided by GemPharmatech Co., Ltd. The upstream and downstream sequences of the PDK-1 gene were inserted into the loxP site. The results of the identification were provided by GemPharmatech Co., Ltd. and validated in the present study (shown in Fig. S1). A total of three male C57BL/6 mice (age, 4-6 weeks old; weight, 10-16 g; wild-type, PDK-1 ${ }^{+/+}$) were also purchased from GemPharmatech Co., Ltd. All animals had the same genetic background. All mice were raised and maintained in the laboratory animal center of Guangxi Medical University (Nanning, China). Mice were individually housed at a controlled temperature $\left(22-26^{\circ} \mathrm{C}\right)$ and humidity $(50-60 \%)$ in ventilated cages with a 12 -h light/dark cycle and free access to standard chow and fresh water. Experiments on all animals were conducted according to the 2013 ARRIVE and AVMA guidelines for euthanasia. Briefly, mice were anesthetized via inhalation of $2 \%$ sevoflurane and were placed in a container; $\mathrm{CO}_{2}$ was then injected into the container at a rate that replaced $25 \%$ of container volume per minute. When it was confirmed that the heartbeats of the mice had stopped and they were no longer breathing, the $\mathrm{CO}_{2}$ was turned off. Finally, the mice were observed for $2 \mathrm{~min}$ to confirm death. The mice were sacrificed in November 2019.

Treatment groups. The control group was treated with OBM. The BX-912 group was treated with OBM containing $0.3 \mu \mathrm{M}$ BX-912 at $37^{\circ} \mathrm{C}$ for 1 week. Subsequently, $1 \times 10^{4}$ cells/well of BMSC ${ }^{\text {PDK-1 flox/flox }}$ in the empty vector and pHBAd-cre-EGFP virus groups were infected with an empty vector or pHBAd-cre-EGFP with a MOI of 100 at $37^{\circ} \mathrm{C}$, respectively. A total of $72 \mathrm{~h}$ post-infection, the medium was replaced with OBM.

Isolation and culture of mouse bone marrow mesenchymal stem cells (BMSCs). After euthanasia, the femurs and tibiae of the mice were isolated under aseptic conditions. Subsequently, a 1-ml injection syringe was used to isolate mice bone marrow from the femurs and tibiae of the PDK $1^{\text {flox/flox }}$ and PDK $1^{+/+}$ mice, according to a previously published protocol (9). The bone marrow was collected by a sterile Pasteur pipette, and filtered through a cell filter and transferred to a centrifuge. Then, 1:4 volume erythrocyte lysis buffer (Beijing Solarbio Science \& Technology Co., Ltd.) was added to lyse the red blood cells. Centrifugation was performed at $100 \mathrm{x} \mathrm{g}$ for $5 \mathrm{~min}$ at $4^{\circ} \mathrm{C}$. Resuspended cells were transferred into a T75 cell bottle in DMEM containing $15 \%$ FBS, as described by Klein et al (10).

Induction of BMSC differentiation into osteoblasts. Primary BMSCs were isolated and cultured in an incubator containing $5 \% \mathrm{CO}_{2}$ at $37^{\circ} \mathrm{C}$; the medium was changed every 2-3 days. Third-generation BMSCs were collected and seeded in 6-well plates previously coated with gelatin at a density of $5 \times 10^{3}$ cells $/ \mathrm{cm}^{2}$, and upon the BMSCs reaching 70-80\% confluence, $2 \mathrm{ml} \mathrm{OBM}$ was added to each well to initiate induction, followed by culture in an incubator containing $5 \% \mathrm{CO}_{2}$ at $37^{\circ} \mathrm{C}$. $\mathrm{OBM}$ was replaced with fresh OBM every 3 days. The main components of OBM include $50 \mu \mathrm{g} / \mathrm{ml}$ ascorbic acid, $10 \mathrm{mM}$ sodium $\beta$-glycerophosphate and $10^{-7} \mathrm{M}$ dexamethasone. After 1 week of induction, to avoid osteoblast shedding, $1 \mathrm{ml}$ of medium was changed every 2 days. The morphology of the osteoblasts was observed under a light microscope (magnification, x100; Leica DMI8; Leica Microsystems GmbH).

Infection with adenoviral vectors. BMSCs from PDK $1^{\text {flox/flox }}$ mice (BMSC ${ }^{\text {PDK-1flox/flox }}$ ) were infected with empty adenovirus vectors or pHBAd-cre-EGFP adenovirus vectors (Hanbio 
Biotechnology Co., Ltd.), as previously described (11). Preliminary investigations to determine the optimal MOI value were performed in 96-well plates. Then, BMSCs were cultured in 96-well plates at a density of $1 \times 10^{4}$ cells/well. Different MOI virus particle solutions were premixed with medium and added to each culture well. The MOI gradient was $25,50,100,200,300$ and 400 (12). After $7 \mathrm{~h}$, the medium was replaced with ordinary culture medium. After $72 \mathrm{~h}$, the MOI with the highest fluorescence efficiency was selected as the optimal MOI. Transfection efficiency $(\%)=($ number of cells emitting green fluorescence in the fluorescence microscope field/number of cells in the light microscope field) $\mathrm{x} 100$. A total of $72 \mathrm{~h}$ post-adenovirus infection into BMSCs, the number of fluorescent cells in three visual fields was counted in the empty vector and pHBAd-cre-EGFP virus groups, and the transfection efficiency was calculated. If the transfection efficiency reached $\sim 80 \%$, the next experiment was conducted.

CCK-8 assay. CCK-8 was used to observe the effects of the PDK1-specific inhibitor BX-912 on BMSC proliferation, and to identify its maximum safe concentration. BMSCs were plated onto 96-well plates in triplicate at a density of $1 \times 10^{4}$ cells/well in complete medium. After 1 day, the BMSCs were treated with different concentrations of BX-912 (0, 0.1, 0.3, 0.5, 0.7, 0.9 and $1.1 \mu \mathrm{M}$ ) for $24,48,72,96$ and $120 \mathrm{~h}$ at $37^{\circ} \mathrm{C}$. Subsequently, $10 \mu \mathrm{l} \mathrm{CCK}-8$ buffer was added to each well for $2 \mathrm{~h}$ at $37^{\circ} \mathrm{C}$. The optical density (OD) values were measured at a wavelength of $450 \mathrm{~nm}$ using a microplate reader.

Staining and quantification of extracellular matrix. For ALP staining and ALP activity assay, the cells were washed five times with PBS, fixed with $4 \%$ paraformaldehyde for $30 \mathrm{~min}$ at $20^{\circ} \mathrm{C}$, washed 3-5 times with PBS and further incubated with freshly prepared 5-bromo-4-chloro-3-indolyl-phosphate/nitro blue tetrazolium (Beyotime Institute of Biotechnology) working solution at $37^{\circ} \mathrm{C}$ for $1 \mathrm{~h}$. The cells were then washed with distilled water 3-5 times, and observed under an inverted light microscope (magnification, x100) after being sealed in resin. The ALP activity was assessed using an ALP assay kit (cat. no. P0321S; Beyotime Institute of Biotechnology). The absorbance/optical density (OD) of each sample was measured at $492 \mathrm{~nm}$ using a microplate reader. Cellular ALP activity was quantified as previously described (13).

For Alizarin Red staining and quantification of mineralized extracellular matrix, the cells were maintained in different groups for 21 days, washed with PBS and then fixed with $4 \%$ paraformaldehyde for $30 \mathrm{~min}$ at $20^{\circ} \mathrm{C}$. After washing with PBS 3-5 times, cells were stained with Alizarin Red S solution (40 mmol/1; pH 4.2; Beyotime Institute of Biotechnology) for $20 \mathrm{~min}$ at $20^{\circ} \mathrm{C}$. Cells were then washed with PBS and images were captured using an inverted light microscope (magnification, x100). The sample solution was measured using a microplate reader at an OD of $402 \mathrm{~nm}$. The quantification of mineralized extracellular matrix was performed as previously described (14).

Western blot analysis. Total protein was extracted using RIPA lysis buffer (Shanghai Biyuntian Biotechnology Co., Ltd.), according to the manufacturer's protocol. Briefly, protein lysis buffer $(1 \mathrm{ml})$ was added to each well, cells were lysed for $30 \mathrm{~min}$ at $4^{\circ} \mathrm{C}$, and cell lysates were collected at $4^{\circ} \mathrm{C}$. Subsequently, the supernatants were collected, and the protein concentration was determined using the bicinchoninic acid assay method. A total of $20 \mu \mathrm{g}$ protein was separated via $10 \%$ SDS-PAGE. Proteins were transferred to polyvinylidene fluoride membranes and incubated in $5 \%$ milk for $1 \mathrm{~h}$ at $37^{\circ} \mathrm{C}$. Subsequently, membranes were incubated with the following primary antibodies overnight at $4^{\circ} \mathrm{C}$ : Anti-p-PDK1 (1:1,000), anti-PDK1 (1:1,000), anti- $\beta$-actin $(1: 1,500)$, anti-AKT $(1: 1,000)$ and anti-p-AKT $(1: 1,000)$. Subsequently, secondary antibodies (anti-rabbit horseradish peroxidase-conjugated $\mathrm{IgG}$ ) were added at a 1:1,000 dilution, and samples were incubated at $37^{\circ} \mathrm{C}$ for $1 \mathrm{~h}$. Then, $0.5 \mathrm{ml}$ chemiluminescent horseradish peroxidase substrate (EMD Millipore) was then added to the membrane and incubated for $4 \mathrm{~min}$ at $20^{\circ} \mathrm{C}$. The membrane was carefully placed in a cassette and left for $30 \mathrm{sec}$; during development, the film was completely immersed in the developing solution. When a black band was observed on the film, it was rinsed with clean water and placed in the fixing solution. The blot was analyzed using ImageJ 5.0 software (National Institutes of Health).

$R N A$ preparation and reverse transcription-quantitative $P C R(q P C R)$. Total RNA was extracted from cell lines using the E.Z.N.A. Total RNA kit I (Omega Bio-Tek, Inc.; cat. no. R6834-02). cDNA was reverse transcribed from 1-2 $\mu \mathrm{g}$ extracted RNA using the RevertAid First Strand cDNA Synthesis kit (Thermo Fisher Scientific, Inc.) under the following conditions: $37^{\circ} \mathrm{C}$ for $5 \mathrm{~min}, 42^{\circ} \mathrm{C}$ for $60 \mathrm{~min}$ and $70^{\circ} \mathrm{C}$ for $10 \mathrm{~min}$. The PCR reaction was performed using the PowerUp ${ }^{\mathrm{TM}} \mathrm{SYBR}^{\mathrm{TM}}$ Green Master mix (cat. no. A25742; Applied Biosystems; Thermo Fisher Scientific, Inc.). The following thermocycling conditions were used for the qPCR: Initial denaturation at $95^{\circ} \mathrm{C}$ for $5 \mathrm{~min}$; followed by 40 cycles at $95^{\circ} \mathrm{C}$ for $5 \mathrm{sec}, 60^{\circ} \mathrm{C}$ for $34 \mathrm{sec}$ and $72^{\circ} \mathrm{C}$ for $15 \mathrm{sec}$; and a final extension at $72^{\circ} \mathrm{C}$ for $1 \mathrm{~min}$. The primers used were as follows: PDK-1, forward, 5'-TGTGCTTGGTGGATA TTGAT-3' and reverse, 5'-AAGGAGGAGAGGAGGAAT GT-3'; RUNX2, forward, 5'-TTCTCCAACCCACGAATG CAC-3', and reverse, 5'-CAGGTACGTGTGGTAGTGAGT-3'; osteocalcin, forward, 5'-GAGGGCAATAAGGTAGTGAAC AGA-3' and reverse, 5'-AAGCCATACTGGTTTGATAGC TCG-3'; collagen I, forward, 5'-AATGGTGCTCCTGGTATT GC-3' and reverse, 5'-GGCACCAGTGTCTCCTTTGT-3'; and GAPDH, forward, 5'-GCATCTCCCTCACAATTTCCA-3' and reverse, 5'-TGCAGCGAACTTTATTGATGGT-3'. The mRNA expression levels of RUNX2, osteocalcin, collagen I and PDK-1 were normalized to those of GAPDH. The $2^{-\Delta \Delta C q}$ method was used to determine the relative expression levels of each target gene $(8,15)$.

Statistical analysis. Experimental data are presented as the mean \pm standard deviation of $\geq 3$ independent biological repeats and were analyzed using SPSS 24.0 statistical software (IBM Corp.). One-way analysis of variance followed by Tukey's test was used to compare differences among multiple groups. $\mathrm{P}<0.05$ was considered to indicate a statistically significant difference. 


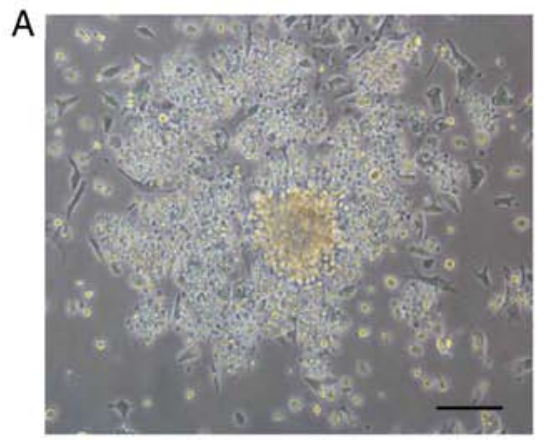

Cultured at 5 days

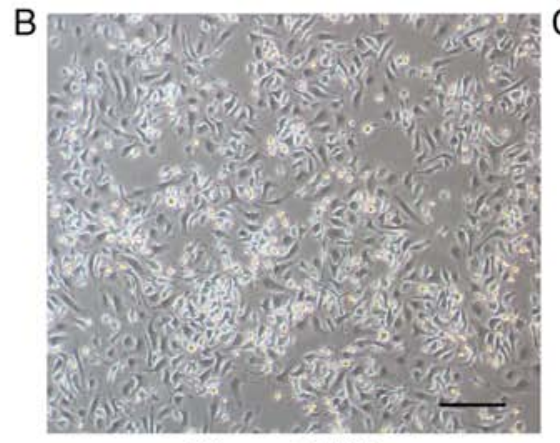

Primary BMSC

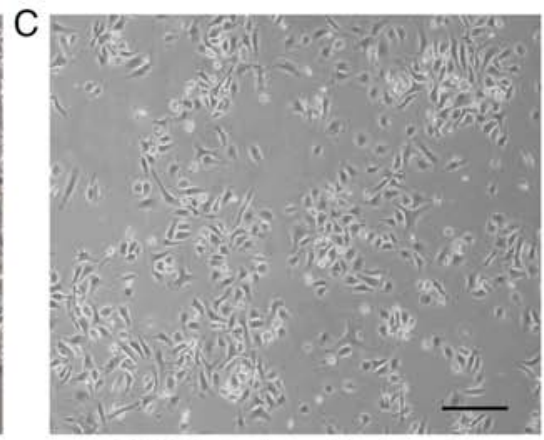

OBM induction after 1 week

Figure 1. Detection of BMSCs under an inverted microscope. (A) Multiple BMSCs gathered and formed colonies. Scale bar, $50 \mu \mathrm{m}$. (B) In the primary generation, the BMSCs were slender and fusiform, and cell growth was obviously accelerated. Scale bar, $50 \mu \mathrm{m}$. (C) After the cells were cultured in OBM, their growth rate clearly slowed down. Scale bar, $50 \mu \mathrm{m}$. BMSCs, bone marrow stem cells; OBM, osteoblast induction medium.

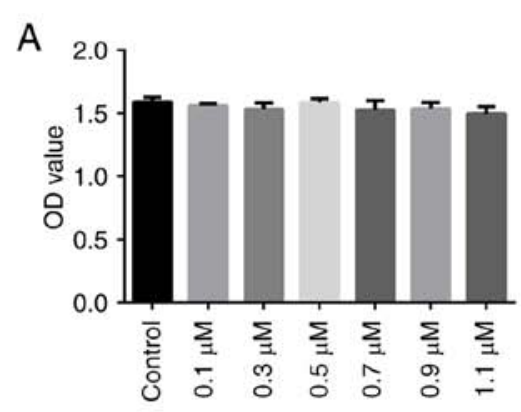

$24 \mathrm{~h}$

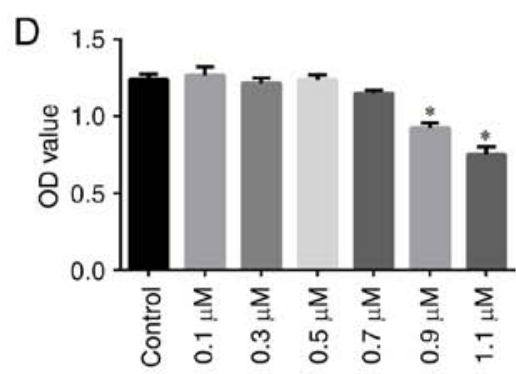

$96 \mathrm{~h}$

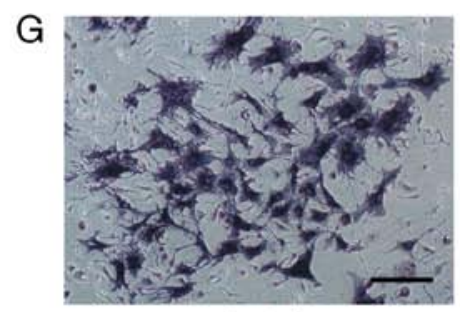

Control

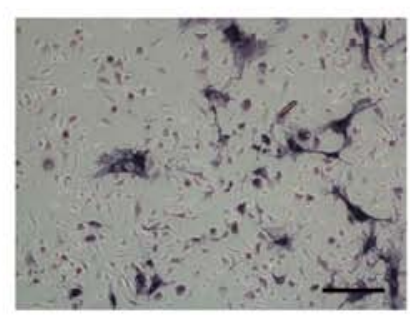

BX-912 (0.3 $\mu \mathrm{M})$

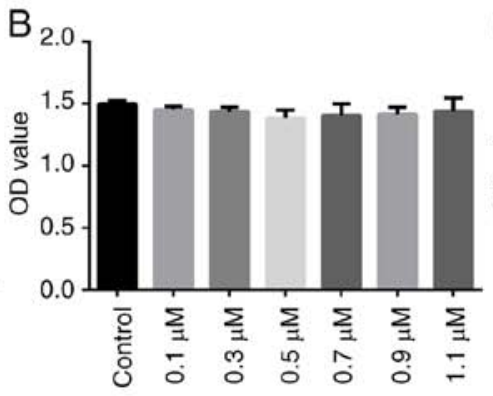

$48 \mathrm{~h}$

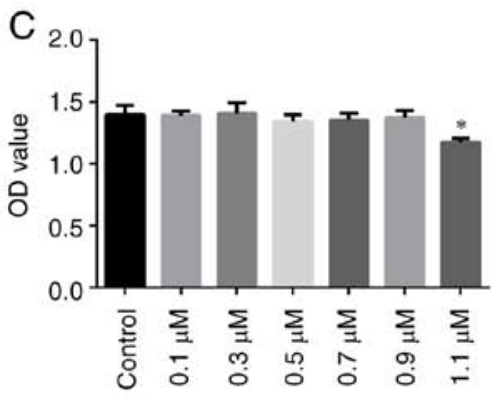

$72 \mathrm{~h}$

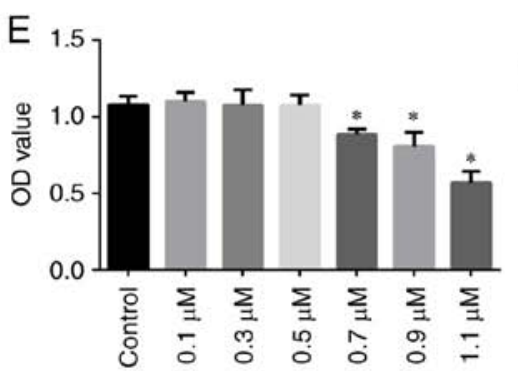

$120 \mathrm{~h}$

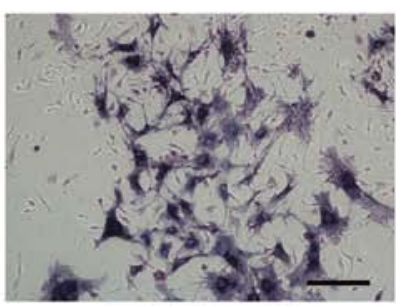

$\mathrm{BX}-912(0.1 \mu \mathrm{M})$
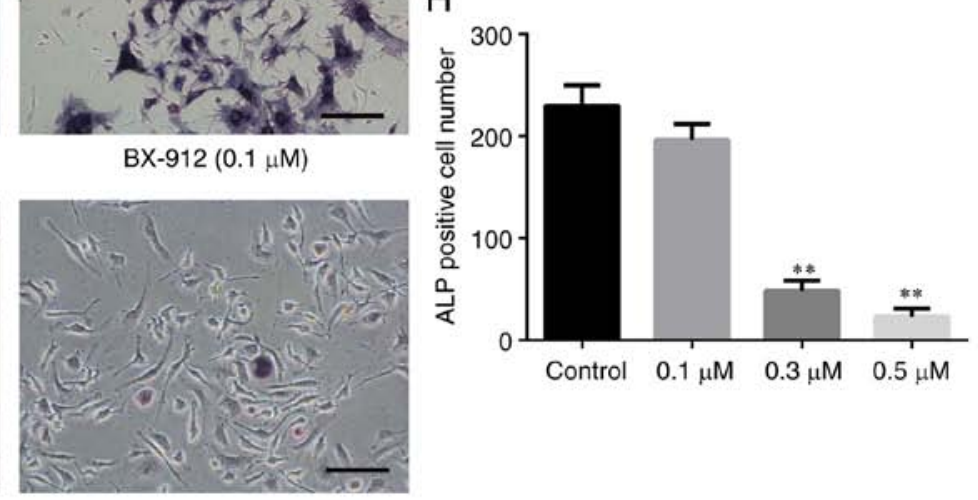

BX-912 (0.5 $\mu \mathrm{M})$

Figure 2. BX-912 inhibits the differentiation of BMSCs into osteoblasts in vitro. The OD values of BX-912-treated BMSCs were determined by Cell Counting Kit-8 assays at (A) 24, (B) 48, (C) 72, (D) 96 and (E) $120 \mathrm{~h}$. Compared with the control group, there was no considerable effect on BMSC activity at $\leq 0.5 \mu \mathrm{M}$. (F) Molecular structure of BX-912. (G) BMSCs were treated with various concentrations of BX-912 for 7 days and stained using the ALP kit. Scale bar, $100 \mu \mathrm{m}$. (H) BX-912 significantly inhibited the formation of ALP-positive osteoblasts in a dose-dependent manner in vitro. Data are presented as the mean \pm standard deviation. ${ }^{*} \mathrm{P}<0.05,{ }^{* *} \mathrm{P}<0.01$ vs. Control. BMSCs, bone marrow stem cells; OD, optical density; ALP, alkaline phosphatase. 
A
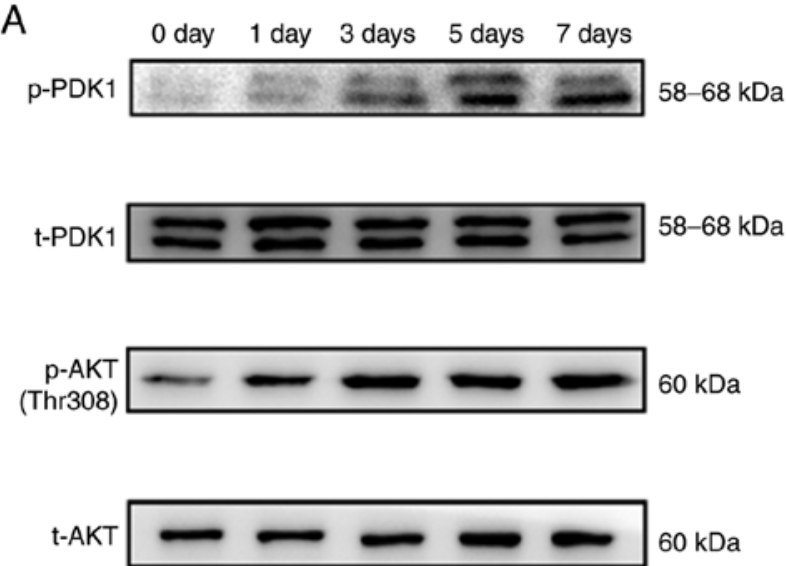

GAPDH

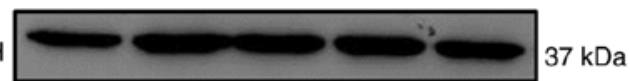

$\mathrm{B}$

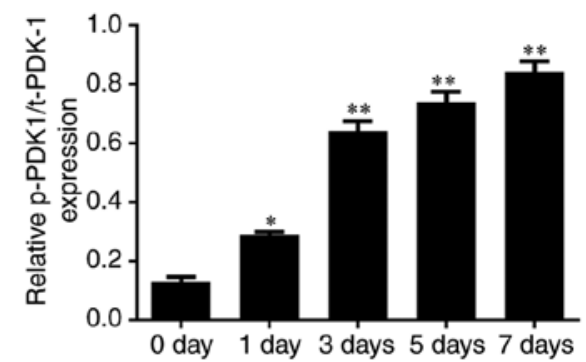

C

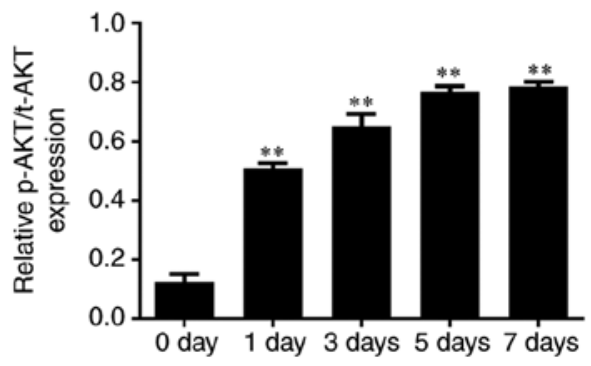

Figure 3. Protein expression levels of p-PDK-1 and p-AKT are gradually increased during osteoblast differentiation. (A) Western blot analysis of PDK1 and AKT protein expression during the differentiation process. Semi-quantification of the protein expression levels of (B) p-PDK1/t-PDK1 and (C) p-AKT/t-AKT, which were significantly increased during the differentiation process. Data are presented as the mean \pm standard deviation. ${ }^{*} \mathrm{P}<0.05$, ${ }^{* *} \mathrm{P}<0.01 \mathrm{vs} .0$ day. $\mathrm{PDK}-1$, 3-phosphoinositide-dependent protein kinase-1. t-, total; p-, phosphorylated.

\section{Results}

Observation of BMSCs under an inverted microscope. After a 24-h cell culture, the majority of cells had attached to the bottom of the flask. After 5 days, most cells had gathered into clusters, and cell colonies were observed in the culture flask (Fig. 1A). In the primary generation, the cells were slender and fusiform with a fence-like arrangement, and cell growth had clearly accelerated (Fig. 1B). Following the addition of OBM, the rate of cell growth was markedly decreased. After a 1-week culture, cell formation resembled that of osteoblasts (triangular or polygonal) (Fig. 1C).

BX-912 inhibits BMSC differentiation into osteoblasts in vitro. The survival rate of the primary BMSCs at 24,48 , 72, 96 and $120 \mathrm{~h}$ was measured using the CCK-8 assay. The results revealed that $\mathrm{BMSC}$ proliferation was not inhibited by $\leq 0.5 \mu \mathrm{M}$ BX-912 (Fig. 2A-E). Therefore, for subsequent experiments, 0.1-0.5 $\mu \mathrm{M}$ BX-912 was added to the OBM. ALP staining was performed on day 7 . The results revealed that ALP formation in cells was significantly inhibited with the increase in BX-912 concentration. When cells were treated with 0.3 and $0.5 \mu \mathrm{M}$ BX-912, the decrease in ALP was statistically significant $(\mathrm{P}<0.01)$; the number of ALP-positive cells decreased from $230 \pm 20 /$ well $(0 \mu \mathrm{M})$ to $25 \pm 10 /$ well $(0.5 \mu \mathrm{M}$; Fig. $2 \mathrm{G}$ and $\mathrm{H})$. These findings indicated that BX-912 could significantly inhibit the differentiation of BMSCs into osteoblasts in a dose-dependent manner in vitro. Notably, $0.3 \mu \mathrm{M}$ BX-912 was selected for follow-up experiments.

p-PDK-1 and p-AKT protein expression is gradually increased during osteoblast differentiation. The protein expression levels of t-PDK1, p-PDK1, t-AKT and p-AKT were detected by western blot analysis on days $0,1,3,5$ and 7 of the osteoblast differentiation process. The results showed that the protein expression levels of p-PDK1 and p-AKT were gradually increased in the osteoblasts $(\mathrm{P}<0.05$; Fig. 3$)$.

pHBAd-cre-EGFP viral infection decreases $P D K-1$ expression in $B M S C s^{P D K-l f l o x / f l o x}$. An adenovirus vector was used to introduce the Cre recombinase enzyme into BMSCs ${ }^{\text {PDK-1flox/flox }}$ to disrupt the PDK-1 gene. Based on the MOI gradient, it was observed that infection efficiency was at its highest at a MOI of 100 ; transfection efficiency was $85 \%$ when cells were infected with a MOI of 100 (Fig. 4A). The BMSCs were obtained from homozygote PDK-1 $1^{\text {flox/flox }}$ mice, in which the upstream and downstream sequences of the PDK-1 gene were inserted into the loxP site, so that the Cre recombinase enzyme could knock out PDK-1 gene expression by recognizing the loxP site (Fig. 4B). The RT-qPCR results demonstrated that the mRNA expression levels of PDK-1 were higher in the empty vector virus group on day $7(12.69 \pm 0.61)$ compared with those in the pHBAd-cre-EGFP virus group (3.6 \pm 0.2$)$; mRNA expression of PDK-1 was decreased by $72 \%$ at day 7 $(\mathrm{P}<0.01$; Fig. 4C). Western blot analysis revealed that $\mathrm{p}-\mathrm{PDK} 1$, t-PDK1 and p-AKT protein expression gradually decreased with time during the differentiation process of BMSCs into osteoblasts $(\mathrm{P}<0.05$; Fig. 4D). In conclusion, disrupting the floxed PDK-1 gene segment by Cre recombinase downregulated PDK-1 expression in BMSCs ${ }^{\text {PDK-1flox/flox }}$, as compared with the non-specific effects that viral infection had on PDK-1 in BMSC $^{\text {PDK-1flox/flox }}$ in the empty vector group.

ALP activity and mineralization are inhibited by $B X-912$ and pHBAd-cre-EGFP viral transfection. ALP expression is generally detected in the early stage of osteoblast differentiation, whereas the mineralization process generally occurs in the middle and late stages of osteoblast differentiation (16). Therefore, ALP staining and OD value determination were performed on day 7 , whereas Alizarin Red staining and 


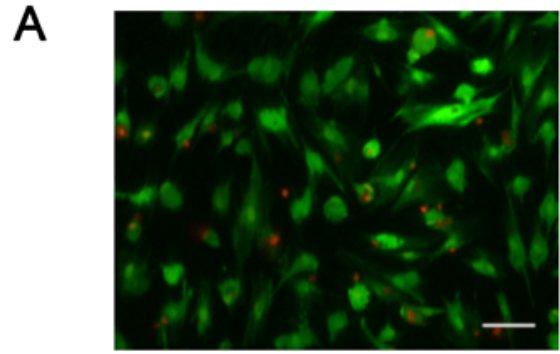

Empty vector virus

B
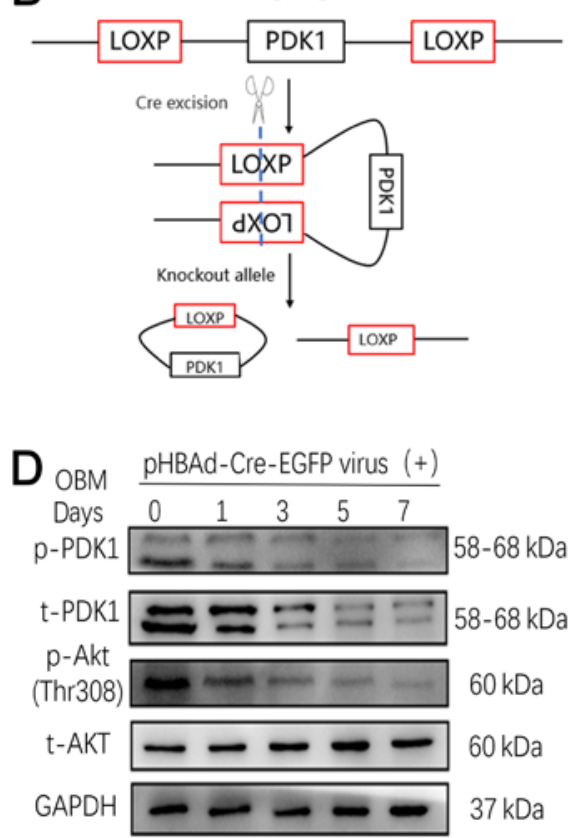

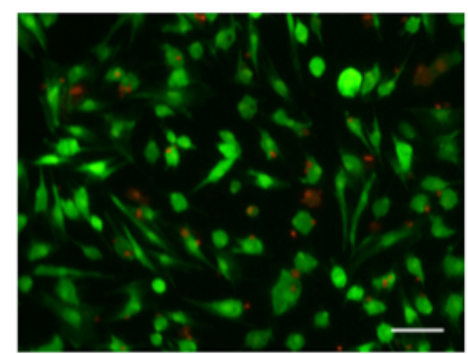

pHBAd-cre-EGFP virus

C

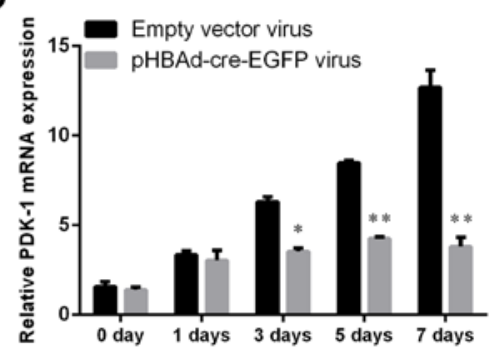

E

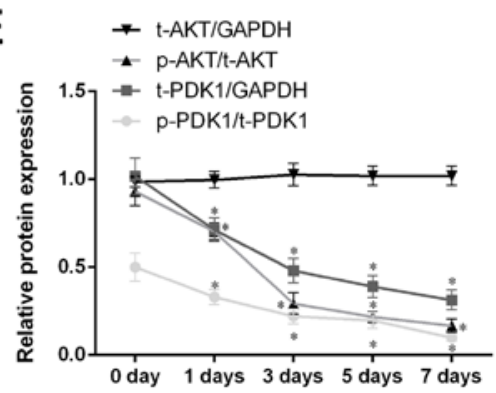

Figure 4. pHBAd-cre-EGFP viral infection decreases PDK-1 expression in BMSC ${ }^{\text {PDK-fllox/flox }}$. (A) Green fluorescence of viral infection at a multiplicity of infection of 100. Scale bar, $100 \mu \mathrm{m}$. (B) Schematic diagram of the mechanism of action of Cre enzyme. (C) Reverse transcription-quantitative PCR revealed that the relative mRNA expression levels of PDK-1 were gradually inhibited following pHBAd-cre-EGFP viral infection compared with those in the empty vector virus group. (D) Western blot analysis of t-PDK-1, p-PDK-1, t-AKT and p-AKT protein expression during the differentiation process, following pHBAd-cre-EGFP viral infection. (E) Relative protein expression levels of t-PDK1, t-AKT, p-PDK1 and p-AKT were semi-quantified. Data are presented as the mean \pm standard deviation. ${ }^{*} \mathrm{P}<0.05,{ }^{* *} \mathrm{P}<0.01$ vs. 0 day. PDK-1, 3-phosphoinositide-dependent protein kinase-1; t, total; p-, phosphorylated.

quantitative detection of mineralization (\% control) were performed on day 21 . The findings revealed that a higher number of ALP-positive cells and calcified nodules were observed in the control and empty vector groups on days 7 and 21. However, the number of ALP-positive cells and calcified nodules were markedly decreased in the BX-912 and pHBAd-cre-EGFP virus groups on days 7 and 21 (Fig. 5A). The OD values of ALP activity demonstrated that it was significantly lower in the BX-912 and pHBAd-cre-EGFP virus groups compared with those in the control and empty vector virus groups on day 7 ( $\mathrm{P}<0.01 ;$ Fig. 5B). Mineralization (\% control) was also shown to be significantly lower in the BX-912 and pHBAd-cre-EGFP virus groups compared with those in the control and empty vector virus groups on day 21 $(\mathrm{P}<0.01$; Fig. 5C). In conclusion, ALP activity and mineralization (\% control) formation were significantly inhibited by BX-912 or pHBAd-cre-EGFP viral infection.

Osteoblast-related gene expression is decreased by BX-912 and $p H B A d$-cre-EGFP viral infection. The mRNA expression levels of the osteoblast-related genes RUNX2, osteocalcin, collagen I were detected by RT-qPCR on days 7 and 21 . The results demonstrated that the mRNA expression levels of RUNX2, osteocalcin and collagen I were significantly downregulated in the BX-912 and pHBAd-cre-EGFP virus groups, compared with those in the control and empty vector virus groups following treatment for 7 and 21 days $(\mathrm{P}<0.01$; Fig. 6A and B).

\section{Discussion}

BMSCs are a commonly used seed cell in tissue engineering. Under specific conditions, BMSCs can be induced to differentiate into osteoblasts, adipocytes, chondrocytes, neurons, etc., thus participating in tissue repair and regeneration. BMSCs are also the main source of osteoblasts (17). Bone formation refers to the process through which BMSCs form osteoblasts through migration, proliferation and differentiation, and guide the formation of new bone tissue (18). However, the understanding of the principle and molecular mechanism underlying the osteogenic differentiation of BMSCs is still limited. 
A

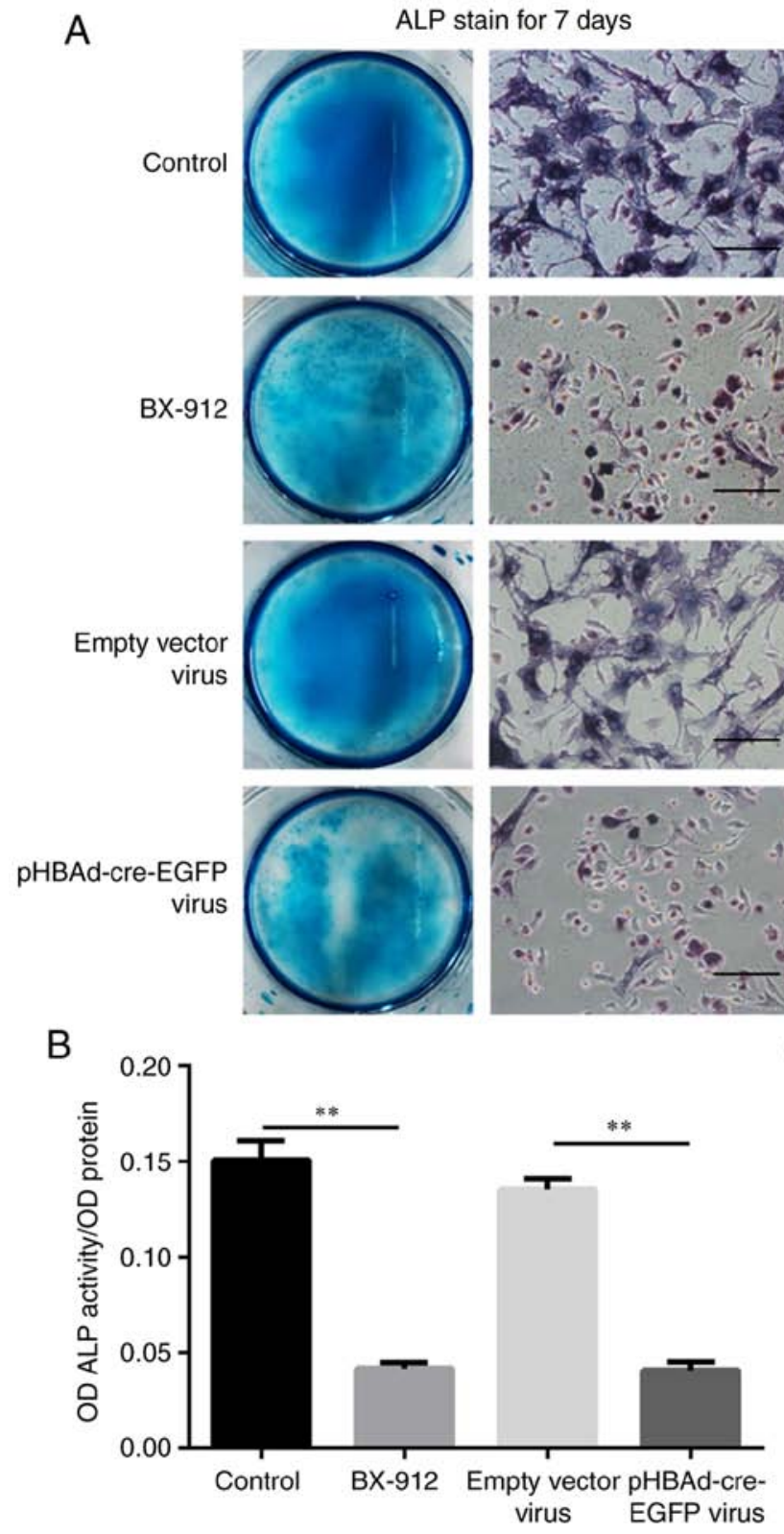

Alizarin Red S staining for 21 days
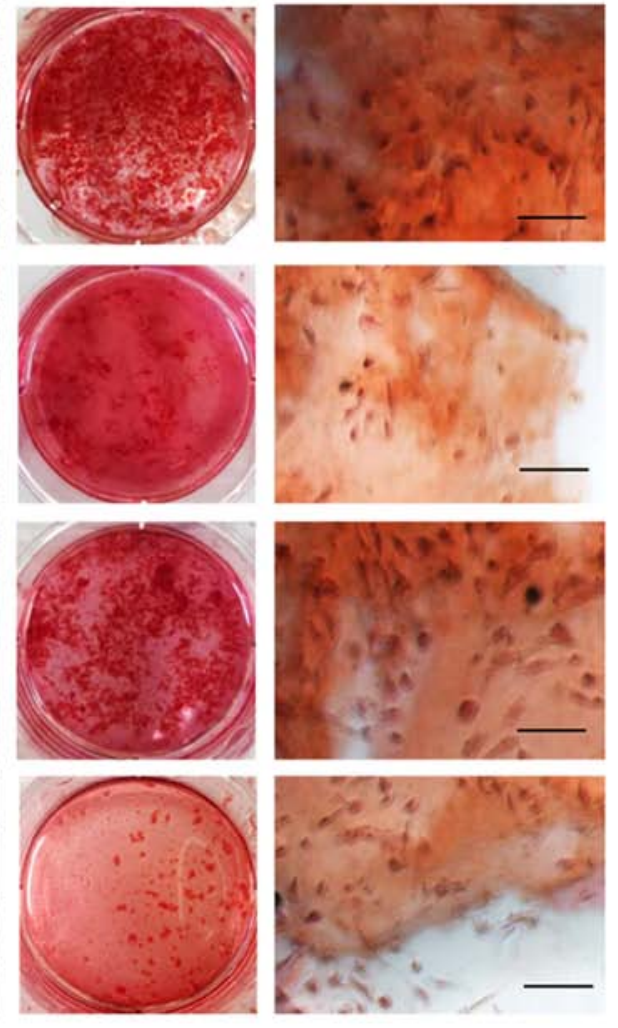

C

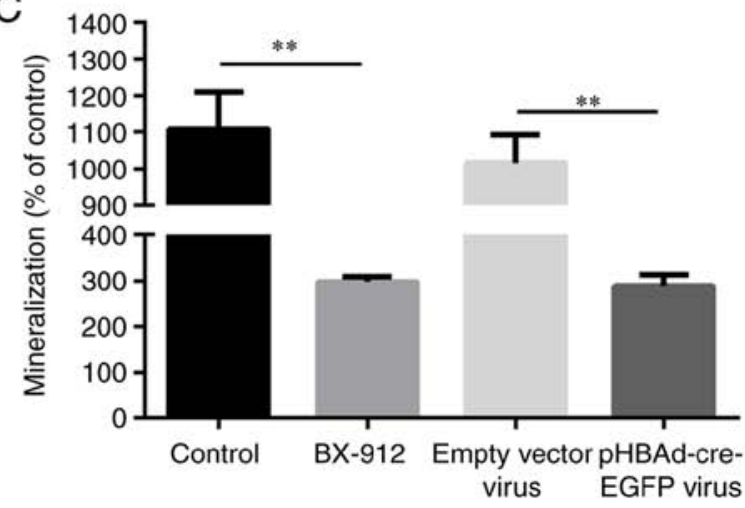

Figure 5. ALP activity and mineralization are significantly inhibited by BX-912 or pHBAd-cre-EGFP viral infection. (A) A markedly higher number of ALP-positive cells and calcified nodules were observed in the control and empty vector virus groups compared with those in the BX-912 and pHBAd-cre-EGFP virus groups. Scale bar, 100- $\mu \mathrm{m}$. (B) OD values of ALP activity were quantified and compared on day 7. (C) Mineralization (\% control) was quantified and compared on day 21. All experiments were performed at least three times. Data are presented as the mean \pm standard deviation. ${ }^{* *} \mathrm{P}<0.01$. Ctrl, control; ALP, alkaline phosphatase; OD, optical density.

Certain studies have reported that activation of the PI3K/AKT signaling pathway may cause changes in numerous signaling molecules associated with bone tissue, including bone morphogenetic protein-2 and ALP bone formation markers, and promote osteoblast proliferation and differentiation (5). During osteoblast differentiation, the inhibition of this signaling pathway may lead to osteoblast damage (19). AKT is a downstream effector of PI3K. Mice with AKT gene knockout showed decreased bone mass synthesis compared with in mice of the same age during childhood and adulthood, indicating that this signaling pathway has the function of regulating osteoblasts $(6,20)$. Based on the results of these studies, it may be hypothesized that the PI3K/AKT signaling pathway serves an important role in osteogenic differentiation.
Research on PDK-1 has mainly focused on tumor metastasis, energy metabolism and cell growth (21), with PDK-1 rarely reported in the field of bone metabolism. PDK-1 has been identified as a protein kinase, which directly participates in the signal transduction pathway downstream of AKT by promoting the phosphorylation of AKT (22), subsequently affecting carbohydrate metabolism, protein transcription and translation and cell proliferation (23). AKT protein can activate the downstream mTORC1 protein, which has been shown to have a pivotal role in apoptosis, autophagy, proliferation and differentiation (24). In addition, AKT is one of the important signaling molecules recognized and phosphorylated by PDK-1. When PDK-1 is activated, the Thr308 site of the AKT protein is rapidly phosphorylated, and downstream target 

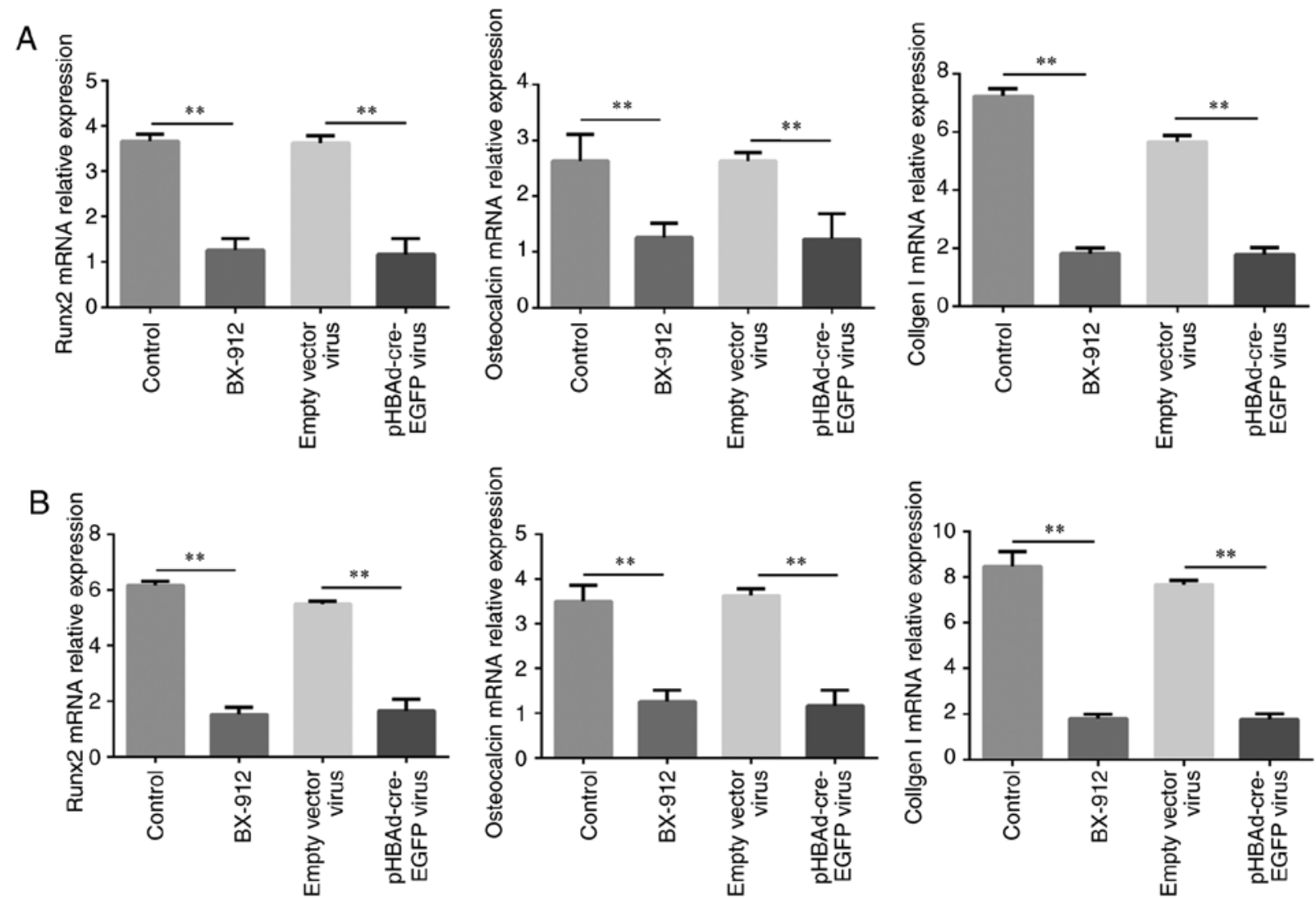

Figure 6. Osteoblast-related genes RUNX2, osteocalcin and collagen I, were analyzed following treatment for (A) 7 and (B) 21 days. The mRNA expression levels of osteoblast-related genes were significantly decreased in the BX-912 and pHBAd-cre-EGFP virus groups. Data are presented as the mean \pm standard deviation. ${ }^{* *} \mathrm{P}<0.01$. Ctrl, control.

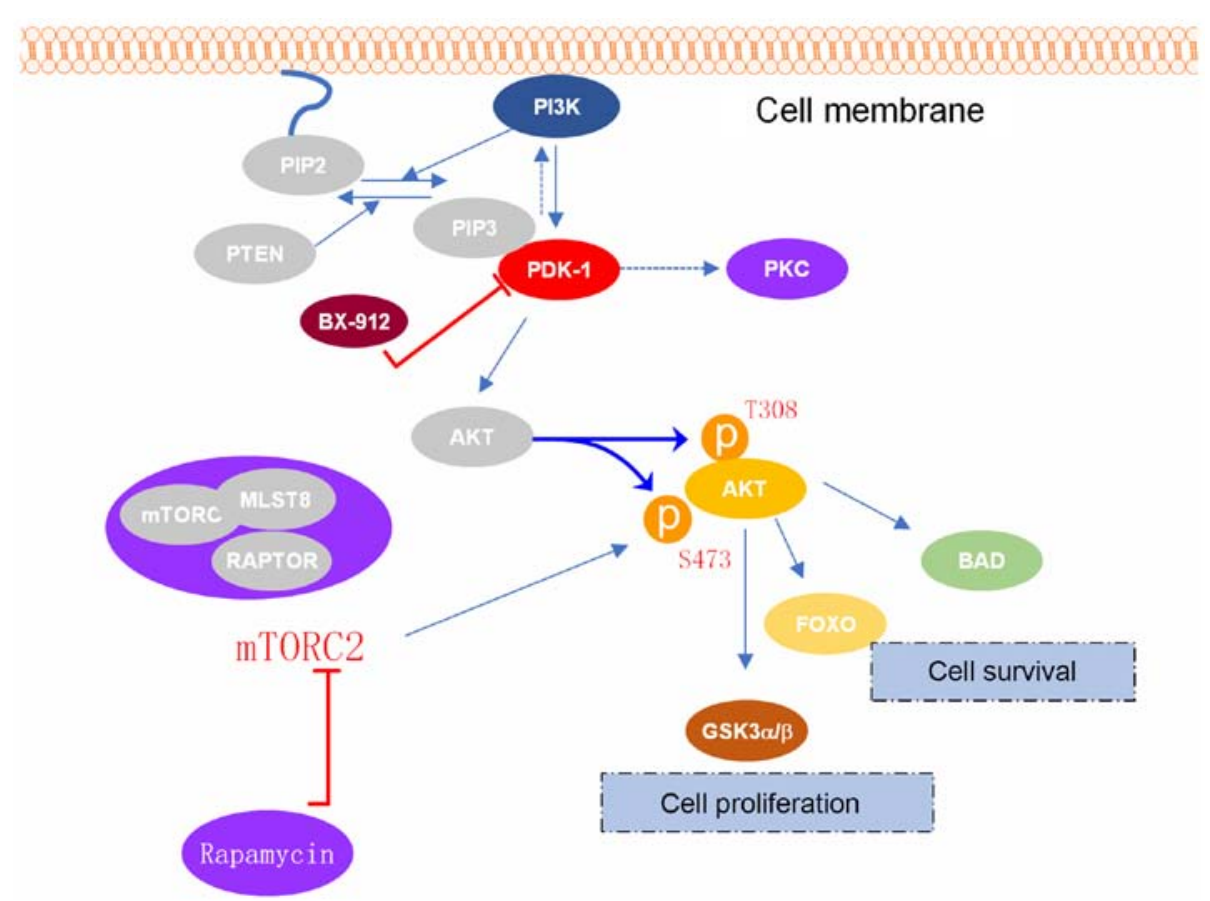

Figure 7. Schematic diagram of the mechanism of the PI3K/PDK-1/AKT signal transduction pathway. PDK-1, 3-phosphoinositide-dependent protein kinase-1.

proteins, such as Bcl-2-associated death promoter, glycogen synthase kinases $\alpha$ and $\beta$, and mTORC1 are activated or inhibited to regulate cell proliferation, differentiation, apoptosis and migration (25). The translocation of AKT can facilitate the phosphorylation of Thr308, which is accomplished with the help of membrane-located PDK-1 (26). PDK-1 has been 
demonstrated to serve a crucial role in PI3K/AKT signal transduction (Fig. 7). Therefore, it was hypothesized that exploring the effect of the PDK-1 gene on osteoblast differentiation and maturation may be of great significance to skeletal metabolic diseases.

In the present study, in order to investigate the physiological role of PDK-1 in bone metabolism, BX-912, a specific inhibitor of PDK-1, was added into the OBM, and it was shown to significantly inhibit the differentiation and maturation of osteoblasts. BX-912 is an effective, complete PDK-1 inhibitor, and its high specificity and selectivity when it comes to the PDK-1 gene has been widely recognized $(27,28)$. These characteristics were also verified in the present study. A previous study also demonstrated that mice cannot survive if the PDK1 gene is knocked out during the embryonic stage (29). Therefore, in order to understand the effect of PDK-1 on osteoblasts, BMSCs were isolated from mice (PDK-1 ${ }^{\text {flox/flox }}$ ) carrying the PDK-1 gene and the upstream and downstream sequence of the PDK-1 gene were inserted into the loxP site respectively. After BMSCs ${ }^{\text {PDK-1flox/flox }}$ were infected with a virus containing the Cre recombinase enzyme (pHBAd-cre-EGFP virus), the mRNA expression levels of PDK-1 were significantly suppressed compared with those in the empty vector virus group on days 3-7; the p-AKT protein was also gradually downregulated.

It has also been reported that PDK-1 may act on downstream proteins through the PI3K-independent pathway (12). Therefore, the present study focused on changes in the expression of downstream AKT proteins. It is well known that ALP is expressed at an early stage of osteoblast differentiation, whereas mineralization occurs at a late stage. Therefore, ALP staining and OD value determination were performed on day 7, and Alizarin Red staining and quantitative detection of mineralization (\% control) were performed on day 21 . In the present study, the same effect that PDK-1 had on osteoblast differentiation was also observed by BX-912 and PDK-1 gene disruption in vitro. To the best of our knowledge, the present study was the first to confirm that PDK-1 has an important role in osteoblast differentiation.

Isomoto et al (30) reported that rapamycin, a specific inhibitor of mTORC, inhibited osteoblast differentiation. Phornphutkul et al (31) and Singha et al (32) reported the same results. Pan et al (33) revealed that inhibition of PI3K kinase could block ALP activity in fetal rat skull cells. The findings of those investigations indicated that the PI3K/PDK-1/Akt/mTORC signaling pathway has an effect on osteoblast differentiation, which were similar to the findings of the present study. Owen and Pan (34) suggested that there were three stages of osteoblast differentiation. Initially, actively proliferating cells produce extracellular matrix components, such as laminin and express cell growth regulatory genes (35). After the cells have entered the maturation stage of the extracellular matrix, collagen I protein, which provides bone mechanical strength and constitutes the structure of bone tissue, is deposited and the expression of ALP, a marker gene of the osteoblast phenotype, is increased. In the final stage of mineralization, the expression of bone sialoprotein and osteocalcin increases. Osteocalcin, a secreted protein, is synthesized by osteoblasts in the non-proliferative stage (18). It participates in bone development by producing carboxylated osteocalcin, and is considered to be a sign of bone formation and transformation. Furthermore, RUNX2, as a specific transcription factor for osteoblasts, mainly regulates the differentiation of mesenchymal stem cells into osteogenic and cartilage precursor cells, and serves an important role in the formation and reconstruction of bone tissue (7). Therefore, the present study detected the expression of these three genes. It was revealed that the mRNA expression levels of RUNX2, osteocalcin and collagen I were significantly downregulated in the BX-912 and pHBAd-cre-EGFP virus groups compared with those in the other groups.

The main components of OBM include ascorbic acid, sodium $\beta$-glycerophosphate and dexamethasone. It has been widely accepted that this medium can promote the differentiation of BMSCs into osteoblasts (36). Dexamethasone has been reported to promote the differentiation and maturation of osteoblasts, increase ALP, regulate the secretion of insulin-like growth factor by osteoblasts and promote the synthesis of extracellular matrix collagen (31). Ascorbic acid may promote the synthesis of collagen I in cultured cells, and regulate ATP and ALP activity and the synthesis of non-collagen matrix proteins (37). $\beta$-glycerophosphate has been shown to provide phosphate ions to osteoblasts, and promote the deposition and calcification of physiological calcium salts, which is a necessary condition for mineralized nodules in BMSCs (38). When medium contains these components, BMSCs undergo a series of changes, resulting in them obtaining the morphology and growth characteristics of osteoblasts (39).

Notably, inhibition of osteoblasts was only observed at the cellular level in the present study; a more in-depth study on its specific biological mechanism is required. It should also be noted that the downstream proteins of the PI3K/AKT signaling pathway were not completely explored, which is another limitation of the present study. Our future studies aim to focus on changes in bone morphology after knocking out the PDK-1 gene in osteoblasts in vivo and on the downstream proteins of the PI3K/AKT signaling pathway, in order to obtain novel targets for the treatment of osteoporosis or osteosclerosis.

In conclusion, the results of the present study found that PDK-1 gene disruption and BX-912 can significantly inhibit the maturation of BMSC into osteoblasts, indicating that PDK-1 plays an important role in the process of osteoblast differentiation.

\section{Acknowledgements}

Not applicable.

\section{Funding}

The present study was supported by the National Natural Science Foundation of China (grant no. 81860402), the Guangxi Natural Science Foundation of China (grant no. 2017GXNSFAA198073), the Guangxi Key Research and Development Project (grant no. GuikeAB17195001), and the High Level Innovation Team and Excellence Scholars Program of Guangxi High Education Institutions and Guangxi Medical High-level Key Talents Training '139' Program Training Project. 


\section{Availability of data and materials}

The datasets used and/or analyzed during the current study are available from the corresponding author on reasonable request.

\section{Authors' contributions}

YB, QiZ and QuZ performed the experiments and wrote the manuscript. YZ and $\mathrm{HN}$ analyzed the data. ML and ZS performed the experiments, analyzed the data, and prepared and drafted the manuscript. SZ and GZ conceived and designed the study, and reviewed and edited the manuscript. All authors read and approved the final manuscript.

\section{Ethics approval and consent to participate}

The animal experiments were approved by the Animals Ethics Committee of Guangxi Medical University and conducted according to the Guide for the Care and Use of Laboratory Animals (approval no. 201910012).

\section{Patient consent for publication}

Not applicable.

\section{Competing interests}

The authors declare that they have no competing interests.

\section{References}

1. Liu P, Lee S, Knoll J, Rauch A, Ostermay S, Luther J, Malkusch N, Lerner UH, Zaiss MM, Neven M, et al: Loss of menin in osteoblast lineage affects osteocyte-osteoclast crosstalk causing osteoporosis. Cell Death Differ 24: 672-682, 2017.

2. Föger-Samwald U, Vekszler G, Hörz-Schuch E, Salem S, Wipperich M, Ritschl P, Mousavi M and Pietschmann P. Molecular mechanisms of osteoporotic hip fractures in elderly women. Exp Gerontol 73: 49-58, 2016.

3. Indran IR, Liang RL, Min TE and Yong EL: Preclinical studies and clinical evaluation of compounds from the genus Epimedium for osteoporosis and bone health. Pharmacol Ther 162: 188-205, 2016.

4. Yoon JY, Baek CW, Kim HJ, Kim EJ, Byeon GJ and Yoon JU: Remifentanil negatively regulates RANKL-induced osteoclast differentiation and bone resorption by inhibiting c-Fos/NFATc1 expression. Tissue Eng Regen Med 15: 333-340, 2018.

5. Gu YX, Du J, Si MS, Mo JJ, Qiao SC and Lai HC: The roles of PI3K/Akt signaling pathway in regulating MC3T3-E1 preosteoblast proliferation and differentiation on SLA and SLActive titanium surfaces. J Biomed Mater Res A 101: 748-754, 2013.

6. Ulici V, Hoenselaar KD, Agoston H, McErlain DD, Umoh J, Chakrabarti S, Holdsworth DW and Beier F: The role of Akt1 in terminal stages of endochondral bone formation: Angiogenesis and ossification. Bone 45: 1133-1145, 2009.

7. Agas D, Sabbieti MG, Marchetti L, Xiao L and Hurley MM: FGF-2 enhances Runx-2/Smads nuclear localization in BMP-2 canonical signaling in osteoblasts. J Cell Physiol 228: 2149-2158, 2013.

8. Xiao D, Zhou Q, Gao Y, Cao B, Zhang Q, Zeng G and Zong S: PDK1 is important lipid kinase for RANKL-induced osteoclast formation and function via the regulation of the Akt-GSK3 $\beta$-NFATc1 signaling cascade. J Cell Biochem 121: 4542-4557, 2020.

9. Peng X, He J, Zhao J, Wu Y, Shi X, Du L, Nong M, Zong S and Zeng G: Polygonatum sibiricum polysaccharide promotes osteoblastic differentiation through the ERK/GSK-3 $\beta / \beta$-catenin signaling pathway in vitro. Rejuvenation Res 21: 44-52, 2018.
10. Klein J, Fasshauer M, Ito M, Lowell BB, Benito M and Kahn CR: beta(3)-adrenergic stimulation differentially inhibits insulin signaling and decreases insulin-induced glucose uptake in brown adipocytes. J Biol Chem 274: 34795-34802, 1999.

11. Shibata H, Toyama K, Shioya H, Ito M, Hirota M, Hasegawa S, Matsumoto $\mathrm{H}$, Takano H, Akiyama T, Toyoshima K, et al: Rapid colorectal adenoma formation initiated by conditional targeting of the Apc gene. Science 278: 120-123, 1997.

12. Sakaue H, Nishizawa A, Ogawa W, Teshigawara K, Mori T, Takashima Y, Noda T and Kasuga M: Requirement for 3-phosphoinositide-kependent dinase-1 (PDK-1) in insulin-induced glucose uptake in immortalized brown adipocytes. J Biol Chem 278: 38870-38874, 2003.

13. Son KM, Park HC, Kim NR, Lee IS and Yang HC: Enhancement of the ALP activity of C3H10T1/2 cells by the combination of an oxysterol and apatite. Biomed Mater 5: 044107, 2010.

14. Dai Y, Zheng $\mathrm{C}$ and $\mathrm{Li} \mathrm{H}$ : Inhibition of miR-23a-3p promotes osteoblast proliferation and differentiation. J Cell Biochem: Nov 6, 2019 (Epub ahead of print). doi: 10.1002/jcb.29497.

15. Livak KJ and Schmittgen TD: Analysis of relative gene expression data using real-time quantitative PCR and the 2(-Delta Delta C(T)) method. Methods 25: 402-408, 2001.

16. Jeon HL, Oh IS, Baek YH, Yang H, Park J, Hong S and Shin JY: Zoledronic acid and skeletal-related events in patients with bone metastatic cancer or multiple myeloma. J Bone Miner Metab 38: 254-263, 2020.

17. Wu J, Zhang W, Ran Q, Xiang Y, Zhong JF, Li SC and Li Z: The differentiation balance of bone marrow mesenchymal stem cells is crucial to hematopoiesis. Stem Cells Int 2018: 1540148, 2018.

18. Berendsen AD and Olsen BR: Bone development. Bone 80: $14-18,2015$

19. Wang J, Ma XY, Feng YF, Ma ZS, Ma TC, Zhang Y,Li X, Wang L and Lei W: Magnesium ions promote the biological behaviour of rat calvarial osteoblasts by activating the PI3K/Akt signalling pathway. Biol Trace Elem Res 179: 284-293, 2017.

20. Peng XD, Xu PZ, Chen ML, Hahn-Windgassen A, Skeen J, Jacobs J, Sundararajan D, Chen WS, Crawford SE, Coleman KG and Hay N: Dwarfism, impaired skin development, skeletal muscle atrophy, delayed bone development, and impeded adipogenesis in mice lacking Akt1 and Akt2. Genes Dev 17: 1352-1365, 2003.

21. Zhu YR, Min H, Fang JF, Zhou F, Deng XW and Zhang YQ: Activity of the novel dual phosphatidylinositol 3-kinase/mammalian target of rapamycin inhibitor NVP-BEZ235 against osteosarcoma. Cancer Biol Ther 16: 602-609, 2015.

22. Alessi DR, James SR, Downes CP, Holmes AB, Gaffney PR, Reese CB and Cohen P: Characterization of a 3-phosphoinositide-dependent protein kinase which phosphorylates and activates protein kinase Balpha. Curr Biol 7: 261-269, 1997.

23. Frödin M, Jensen CJ, Merienne K and Gammeltoft S: A phosphoserine-regulated docking site in the protein kinase RSK2 that recruits and activates PDK1. EMBO J 19: 2924-2934, 2000.

24. Abeyrathna P and Su Y: The critical role of Akt in cardiovascular function. Vascul Pharmacol 74: 38-48, 2015.

25. Wang F, Shan S, Huo Y, Xie Z, Fang Y, Qi Z, Chen F, Li Y and Sun B: MiR-155-5p inhibits PDK1 and promotes autophagy via the mTOR pathway in cervical cancer. Int J Biochem Cell Biol 99: 91-99, 2018.

26. Williams MR, Arthur JS, Balendran A, van der Kaay J, Poli V, Cohen P and Alessi DR: The role of 3-phosphoinositide-dependent protein kinase 1 in activating AGC kinases defined in embryonic stem cells. Curr Biol 10: 439-448, 2000.

27. Qiu Z, Li H, Zhang Z, Zhu Z, He S, Wang X, Wang P, Qin J, Zhuang L, Wang W, et al: A pharmacogenomic landscape in human liver cancers. Cancer Cell 36: 179-193.e111, 2019.

28. Coppé JP, Mori M, Pan B, Yau C, Wolf DM, Ruiz-Saenz A, Brunen D, Prahallad A, Cornelissen-Steijger P, Kemper K, et al: Mapping phospho-catalytic dependencies of therapy-resistant tumours reveals actionable vulnerabilities. Nat Cell Biol 21: 778-790, 2019.

29. Qian XJ, Li XL, Xu X, Wang X, Feng QT and Yang CJ: $\alpha$-SMA-Cre-mediated excision of PDK1 reveals an essential role of PDK1 in regulating morphology of cardiomyocyte and tumor progression in tissue microenvironment. Pathol Biol (Paris) 63: 91-100, 2015.

30. Isomoto S, Hattori K, Ohgushi H, Nakajima H, Tanaka $Y$ and Takakura Y: Rapamycin as an inhibitor of osteogenic differentiation in bone marrow-derived mesenchymal stem cells. J Orthop Sci 12: 83-88, 2007. 
31. Phornphutkul C, Lee M, Voigt C, Wu KY, Ehrlich MG, Gruppuso PA and Chen Q: The effect of rapamycin on bone growth in rabbits. J Orthop Res 27: 1157-1161, 2009.

32. Singha UK, Jiang Y, Yu S, Luo M, Lu Y, Zhang J and Xiao G: Rapamycin inhibits osteoblast proliferation and differentiation in MC3T3-E1 cells and primary mouse bone marrow stromal cells. J Cell Biochem 103: 434-446, 2008.

33. Pan JM, Wu LG, Cai JW, Wu LT and Liang M: Dexamethasone suppresses osteogenesis of osteoblast via the PI3K/Akt signaling pathway in vitro and in vivo. J Recept Signal Transduct Res 39: 80-86, 2019.

34. Owen TA and Pan LC: Isolation and culture of rodent osteoprogenitor cells. Methods Mol Biol 455: 3-18, 2008.

35. Selim AA, Castaneda JL, Owen TA, Popoff SN and Safadi FF: The role of osteoactivin-derived peptides in osteoblast differentiation. Med Sci Monit 13: BR259-BR270, 2007.

36. Xi Y, Huang H, Zhao Z, Ma J and Chen Y: Corrigendum to 'Tissue inhibitor of metalloproteinase 1 suppresses growth and differentiation of osteoblasts and osteoclasts by targeting the AKT pathway' [Exp. Cell Res. 389 (2020) 111930-11940]. Exp Cell Res 394: 112189, 2020.
37. Hadzir SN, Ibrahim SN, Abdul Wahab RM, Zainol Abidin IZ, Senafi S, Ariffin ZZ, Abdul Razak M and Zainal Ariffin SH: Ascorbic acid induces osteoblast differentiation of human suspension mononuclear cells. Cytotherapy 16: 674-682, 2014.

38. Huang RX and Tao J: Nicotinamide mononucleotide attenuates glucocorticoid-induced osteogenic inhibition by regulating the SIRT1/PGC-1 $\alpha$ signaling pathway. Mol Med Rep 22: 145-154, 2020.

39. Fu X, Yang H, Zhang H, Wang G, Liu K, Gu Q, Tao Y, Chen G, Jiang X, Li G, et al: Improved osteogenesis and upregulated immunogenicity in human placenta-derived mesenchymal stem cells primed with osteogenic induction medium. Stem Cell Res Ther 7: 138, 2016.

c) (i) $\ominus$ This work is licensed under a Creative Commons EY NC ND Attribution-NonCommercial-NoDerivatives 4.0 International (CC BY-NC-ND 4.0) License. 